\title{
The Attrition of Young Physician-Scientists: Problems and Potential Solutions
}

\author{
MARK DONOWITZ, ${ }^{*}$ GREG GERMINO, ${ }^{*}$ FABIO COMINELLI, ${ }^{\neq}$and JAMES M. ANDERSON ${ }^{\S}$
}

*Department of Medicine, Johns Hopkins University School of Medicine, Baltimore, Maryland; " Department of Medicine, University of Virginia at Charlottesville School of Medicine, Charlottesville, Virginia; and ${ }^{\S}$ Department of Cell and Molecular Physiology, University of North Carolina School of Medicine at Chapel Hill, Chapel Hill, North Carolina

Physician-scientists have played a prominent role as thought leaders in American medicine over the past century. This group has produced many basic scientific advances and pioneered the translation of these advances into clinical practice. Now that we are in the postgenomic era, there is a greater need than ever for the continued participation of this group because of their unique ability to bridge the "bench to bedside." However, the number of physicians pursuing this career is static and their average age is rising. Recent data indicate that the many benefits of this career path are seen as being outweighed by so many negative factors, as to prompt the question, "Is this a career that a reasonable person should undertake in 2007 and beyond?" The following analysis suggests that the current answer is "no." We have identified the lack of professional security as a major factor that prompts young physicians to abandon the physicianscientist track. Because this problem has not been sufficiently emphasized, we believe current efforts are unlikely to reverse this disturbing trend. We propose strategies that seek to address this problem and help sustain young physician-scientists at career transition points at which they are most vulnerable to give up.

$\mathrm{T}$ here is little doubt of the important and growing role played by the physician-scientist in generating medical advances in the postgenomic era. Without extensive involvement of scientists who understand both basic physiologic mechanisms and the subtle aspects of human diseases, there would be significant delays in the application of molecular breakthroughs to the diagnosis of diseases and the development of cures. With this in mind, the current situation of physician-scientists selecting investigative careers bears some scrutiny. The total number of physician-scientists involved in National Institutes of Health (NIH)-related research has not increased in 24 years ( 15,000 in 1980 and 14,000 in 2004), despite the recent doubling of the NIH budget. In contrast, the number of $\mathrm{PhD}$ scientists applying for $\mathrm{NIH}$ funding has increased continually during this period. For instance, scientists with PhDs applying to the $\mathrm{NIH}$ for the first time has increased by $120 \%$ during the past 30 years, ${ }^{1}$ and this is only a fraction of the total $\mathrm{PhD}$ pool currently applying for NIH funding. In a recent article outlining the great increase in the current number of NIH applications and grants per principal investigator, there was no mention of the total number of $\mathrm{MD}$ or $\mathrm{MD}, \mathrm{PhD}$ scientists attempting to obtain funding. ${ }^{2}$ Of equal concern to the reluctance of physicians to undertake investigative careers is the significant dropout rate for physicians who have set out on this career path. Parenthetically, there is no evidence that only the least capable physician-investigators drop out, with many of the potentially most creative physician-scientists abandoning science. The result is that a huge national investment in intellectual capital is being wasted, while physician-scientists are themselves investing many years in training that often does not deliver satisfying careers, despite the fact that this is a time of increased scientific opportunity.

This report analyzes the magnitude of the attrition of physician-scientists and identifies the reasons for this behavior. More importantly, we identify some solutions that might make this career path more attractive and might prevent the burning of American intellectual cap$i^{2}{ }^{3}$ at a time advances in science are likely to be made by an increasing number of countries. This analysis was assisted by data provided by the NIH (W. T. Schaffer, $\mathrm{PhD}$, Senior Scientific Advisor for Extramural Research) and by Dr D. Feng of the Association of American Medical Colleges, as well as the publication by T. Kochen of an analysis of similar NIH databases. ${ }^{4}$ The problems identified and solutions suggested arose from a working group including members of the AGA Institute Research Policy Committee (James Anderson, Kim Barrett) plus several additional scientists (Fabio Cominelli, Mordecai Blaustein, Nick Davidson, Ann Hubbard, Daniel Podolsky, and Alan Walker).

\section{The Problem}

One obvious deterrent is the large and increasing salary differential between the typical income of physi-

\footnotetext{
Abbreviation used in this paper: $\mathrm{NIH}$, National Institutes of Health (c) 2007 by the AGA Institute 0016-5085/07/\$32.00 doi:10.1053/j.gastro.2006.12.023 GASTROENTEROLOGY 2007;132:477-480
} 
cian-investigators and full-time practitioners. However, anecdotal evidence presented to our working group indicated that this differential is not the most important deterrent to physician-scientists electing to enter and remain in an investigative career. There have always been physicians who are motivated by considerations beyond income, and the physician-scientist often fits into this mold.

Loan indebtedness is frequently cited as an important factor. To counter this, the NIH initiated a highly successful loan forgiveness program that is helping to lower barriers for interested trainees and may increase the number of candidates who enter the investigative pathway. 1,5 However, this does not address dropout once investigators have already entered this pathway.

Our analysis suggests that the lack of security of individual laboratories as the issue of greatest concern for the physician-scientist. Running a successful research program presents all the challenges of a small business and more: issues of personnel; compliance with health, safety, ethics, and animal and human studies standards; and managing budgets and finding salaries for postdoctoral fellows and technicians. In addition to performing and analyzing experiments, investigators must buy and maintain equipment and supplies and train personnel. Support is most often sought by competing for NIH and foundation funds, which are increasingly difficult to obtain. Even more challenging than for a small business, research programs are not for profit. They do not generate capital to carry them over during downturns and can be in danger of losing the ability to function if a single grant is turned down. However, a large percentage of grants are initially turned down by the NIH review process. Also, the amount of money provided from grants for the physician-scientist's salary is often insufficient to "purchase" the percent effort required to accomplish the studies. Clearly this is not a business model designed by someone with an MBA.

\section{Moving Toward a Solution}

To assist the development of appropriate solutions, we first identified the times when physicians are most likely to drop out of the investigator track. Typically, after successful completion of a medical or surgical subspecialty that includes a research fellowship, the physician-scientist enters the NIH career pathway, becoming a junior faculty member and applying for protected time for further training and development of his or her area of research. At this stage, the 5-year $\mathrm{K}$ series of mentored NIH training awards supports development of independent areas of research under the guidance of a mentor. The NIH RO1 grants then provide a further 5 years of support. It appears that if physician-investigators are able to either renew their first RO1 grant or obtain a second
RO1 grant, they are likely to remain in the investigative career track (data provided by the NIH [W. T. Schaffer, $\mathrm{PhD}$, Senior Scientific Advisor for Extramural Research] and by Dr D. Feng of the Association of American Medical Colleges). ${ }^{4}$ The greatest attrition occurs during the transition from $\mathrm{K}$ to $\mathrm{RO} 1$ funding and when attempting to renew the first RO1 grant or obtain a second RO1 grant, both of which are highly competitive stages.

We therefore scrutinized the available data regarding the outcomes for grant applications by physician-scientists at each step in the pathway (data provided by the NIH [W. T. Schaffer, PhD, Senior Scientific Advisor for Extramural Research] and by Dr D. Feng of the Association of American Medical Colleges). ${ }^{4}$ The success of a physician-investigator in obtaining a $\mathrm{K}$ award is approximately $40 \%$. Of K-award holders, $\sim 80 \%$ applied for and $\sim 60 \%$ received an R-series grant, after up to 3 applications (data provided by the NIH [W. T. Schaffer, PhD, Senior Scientific Advisor for Extramural Research]). Between $76 \%$ and $85 \%$ of first RO1 grant holders apply for renewal or a second RO1 grant; of these, $63 \%-67 \%$ are successful. However, there are no data indicating the percentage of physician-scientists who start this career pathway by applying for $\mathrm{K}$ support that are still involved at the later stages. If the stated rates of success for each career step (K, first RO1 grant, and its renewal) were all independent, then the probabilities of success at each stage could be multiplied to calculate the percentage of physician-scientists still applying for NIH funding when they finish competing for their second $\mathrm{R}$ award. This indicates a success rate of $10 \%{ }^{4}$ or $11 \%$ (data from Dr D. Feng of the Association of American Medical Colleges). This level of success appears lower than what most of us have observed, indicating that success at one stage may not predict success at other stages. Also, research funding is available from the Veterans Administration hospitals, private foundations, and Pharma, providing additional opportunities to maintain investigate careers. In addition, those who start this career path may become leaders in other aspects of academic medicine that do not emphasize research. Nonetheless, despite potential flaws in the initial assumption limiting the accuracy of this estimate, these figures are still indicative of the difficulty of this career path. To focus on the physician-investigator, how these success rates compare with those of $\mathrm{PhDs}$, either at each career stage or for a total career, was not considered in this analysis.

\section{Prioritized Suggestions}

Despite the high risks, a group of physicians is nonetheless attracted to investigative careers. Unfortunately, many of the current policies of both the NIH and academic institutions are likely contributing to the high turnover. While the resolution to reduce the burden of 
debt is welcome, other NIH suggestions have been less helpful. A recommendation to consider shortening the training process is not likely to help the physician-investigators, who are already often insufficiently prepared to compete for NIH funding (Bravo, NIH communication). Proposed decreases in the duration of funding (ie, compete for RO3 and R21 grants for 2-3 years of support) are also unlikely to be effective, given the huge time commitment involved in applying for any R-series grant. This will likely increase the number of hurdles and lengthen the time before true stability is achieved, thereby perhaps even increasing the burn rate of intellectual capital.

We therefore provide some alternative suggestions that we believe better address the underlying problem, adding some security for physicians as they develop their "small businesses," and are aimed at the 2 key transition phases where attrition is highest. The solutions require commitments by both the NIH and medical schools. Although not all solutions will apply to each institution, nonetheless the general principles apply broadly; local conditions must determine the best set of effective strategies for each individual.

\section{Changes Primarily by the NIH}

1. Reinstitute a specific award for first-time NIH applicants for the R series of awards that is for 5 years and is funded at levels similar to grants for established investigators. This was also suggested in the 2005 National Research Council report entitled "Bridge to Independence: Fostering the Independence of New Investigators in Biomedical Research." 6 The concept of the old R29 (first award) was correct but provided too little money to protect the young scientists' time and to conduct the research. The review process should allow no triage or triage only a small fraction of the submissions $(10 \%-15 \%)$ due to the very harmful effect of telling the first-time applicant that his or her work is not even good enough to be reviewed and denying him or her the helpful input that discussion of applications often provides. The criteria for review of these applications should focus more on the importance of the question asked and should not expect extensive amounts of preliminary data but rather should evaluate the scientific expertise of the candidate gained via training.

2. Provide security by making an additional $\$ 50,000$ available for $\mathrm{K}$ awardees attempting to achieve $\mathrm{R}$ funding and for first-time RO1 grant holders attempting to either renew or obtain a second RO1 grant. This could be built in as anticipated carryover and awarded if the applicant is unsuccessful in obtaining continuous funding, with the requirement that a review at the academic institution must document continued commitment to an investigative career. This money should be available for maintenance of research infrastructure and not used for faculty salaries.

3. Request that the new Office for Portfolio Analysis and Strategic Initiatives analyze data on early career development, recommend an "ideal" level of support required to sustain the pipeline of physician-scientist investigators, and recommend initiatives aimed at recruiting and retaining the physician-investigator.

\section{Changes Primarily by Academic Institutions}

1. Provide more institutional oversight concerning who is allowed to apply for the $\mathrm{K}$ series.

2. Improve the mentoring and involvement in career development for $\mathrm{K}$ awardees. Accept $80 \%$ research commitment of a 40-hour week, with only 8 hours for clinical, teaching, and committee activities. Institute a young faculty committee to monitor progress. Encourage $\mathrm{K}$ awardees to apply for RO1 support at the beginning of year 4 of the $\mathrm{K}$ award.

3. For holders of the first $\mathrm{R}$ series of awards, require that the mentor and young faculty committee meet annually to provide a written report to the NIH describing progress and time spent in research.

Physician-scientists can choose to pursue basic or clinical research; we have not separated out the outcomes for each pathway, and we do not believe it is productive to focus on only one path. The basic challenges are very similar, and we believe the previously described changes should be pursued as a requirement to aid the viability of both.

\section{Other Considerations}

Given that the success of the numerous prior attempts to address this issue has been so limited, it is reasonable to question whether our new proposals will be any more effective. The success of our recommendations depends on two critical questions: (1) have we correctly identified the reasons why physicians are reluctant to pursue or drop out from investigative careers and, if so, (2) are the initiatives bold enough to address them?

\section{Have We Identified the Important Issues?}

Unfortunately, we know of no systematic effort to survey the reasons why physicians who have expressed interest in the research pathway either fail to enter it or exit it prematurely. This important gap in our information needs to be addressed, perhaps by institutional exit polling.

Lifestyle issues are likely an additional important factor, especially competing time demands for family life and career. While institutions have acknowledged this by adjusting schedules for conferences and meetings to accommodate daycare issues and evolving less rigid time 
frames for tenure, there have been no solutions to the intense time demands of an investigative career.

There may well be other factors, and in the absence of data we are obliged both to respond to what we know and to obtain information on what we do not.

\section{Are the Suggested Measures Likely to Be Sufficient?}

Even assuming that "security of the small business" is indeed an important factor, the question remains whether the proposed interventions will adequately address the problem. There is little question that they will have some impact, just as loan forgiveness likely has increased the applicant pool entering the pipeline. Our proposals are modest; they provide life support and a small amount of security during the multiple rounds of application. Unfortunately, in light of the current reductions in NIH funding, they are unlikely alone to have an immediate major impact.

\section{How Much Money Should Be Invested in the Young Physician-Scientist?}

Given the limited money available, a national debate is needed on the distribution of these funds between young investigators, who represent the future progress, and established investigators, who are currently conducting clinically important studies. There is no clear policy of how the funds are to be distributed, and this lack is preventing decisions on how much to invest in the young investigator. This needs to be discussed in the context of our true manpower needs. The frequent attention given to this problem ${ }^{1,7}$ suggests that current levels are inadequate, but formal analysis is needed to enable informed decisions regarding how to balance competing needs and interests with economic realities. If objective studies truly predict a serious shortage, we may need to implement bolder strategies aimed at both recruitment and retention.

\section{Conclusions}

Investigative careers for physicians are in the best interests of the country, and the United States cannot afford to continue to waste so much intellectual capital. We have identified an important reason that likely accounts for much of this wasted investment and suggest changes that will make this career pathway more attractive. The lack of comprehensive data on this topic warrants a national effort to better define it. A broad discussion involving multiple constituencies is required to guide future investment strategies that balance the needs of new versus established investigators. Finally, it is recommended that this discussion include the broader question of the role of physician-scientists in the biomedical enterprise and the projected number required for its success. Together, these data can be used to devise the most effective strategy for pushing back the frontiers of the understanding and treatment of human disease.

\section{References}

1. Ley TJ, Rosenberg LE. The physician-scientist career pipeline in 2005. Build it, and they will come. JAMA 2005;294:1343-1351.

2. Zerhouni EA. NIH in the post-doubling era: realities and strategies. Science 2006;314:1088-1090.

3. Friedman TL. The world is flat. New York: Farrar, Straus, and Giroux, 2005

4. Kotchen TA, Lindquist T, Malik K, Ehrenfeld E. NIH peer review of grant applications for clinical research. JAMA 2004;291:836843.

5. Nathan DG. Educational debt relief for clinical investigators-a vote of confidence. N Engl J Med 2002;346:372-374.

6. National Research Council of the National Academies. Bridges to independence: fostering the independence of new investigators in biomedical research. Washington, DC: The National Academies Press, 2005.

7. Zerhouni EA. Translational and clinical science-times for a new vision. N Engl J Med 2005;353:1621-1623.

Address requests for reprints to: Mark Donowitz, MD, Department of Medicine, Johns Hopkins University School of Medicine, Baltimore, Maryland 21205-2195. e-mail: mdonowit@jhmi.edu; fax: (410) 9559677. 